\title{
Value of Prognostic Nutritional Index as a Predictor of Lymph Node Metastasis in Gastric Cancer
}

\author{
TOSHIYUKI KOSUGA, TOMOKI KONISHI, TAKESHI KUBOTA, KATSUTOSHI SHODA, \\ HIROTAKA KONISHI, ATSUSHI SHIOZAKI, KAZUMA OKAMOTO, HITOSHI FUJIWARA, \\ MICHIHIRO KUDOU, TOMOHIRO ARITA, RYO MORIMURA, YASUTOSHI MURAYAMA, \\ YOSHIAKI KURIU, HISASHI IKOMA, MASAYOSHI NAKANISHI and EIGO OTSUJI
}

Division of Digestive Surgery, Department of Surgery, Kyoto Prefectural University of Medicine, Kyoto, Japan

\begin{abstract}
Background/Aim: This study examined whether the prognostic nutritional index (PNI) is a useful predictor of pathological lymph node metastasis $(p N+)$ in gastric cancer (GC). Patients and Methods: This study retrospectively examined 167 patients with advanced GC (cT2-T4) undergoing curative gastrectomy. The predictive ability of PNI for $\mathrm{pN}+$ was evaluated in comparison with that of clinical lymph node metastasis $(\mathrm{cN}+)$ determined by computed tomography $(\mathrm{CT})$. Results: The optimal cut-off value of PNI for predicting $\mathrm{pN}+$ was 46 according to the receiver operating characteristic curve analysis. Multivariate analysis revealed a $\mathrm{PNI}<46$ [odds ratio $(O R)=2.905 ; 95 \%$ confidence interval $(C I)=1.347-6.638$, $p=0.006], c N+(O R=2.323 ; 95 \% C I=1.204-4.579, p=0.012)$, and undifferentiated-type adenocarcinoma (OR=2.032; $95 \% C I=1.060-3.947, p=0.033)$ to be independent predictors of $p N+. P N I$ detected $p N+$ with a higher specificity (84.9\%) and positive predictive value (PPV) $(75.6 \%)$ than $c N+(68.5 \%$ and $68.1 \%$, respectively). When the subjects were limited to patients with $c N+$, the specificity and PPV of a PNI $<46$ for $p N+$ became markedly high (91.3\% and $90.5 \%$, respectively). Conclusion: PNI predicts $p N+$ with a high specificity in patients with a clinical diagnosis of advanced GC; therefore, $P N I$ may aid in the definitive diagnosis of $p N+$, especially in combination with CT findings.
\end{abstract}

Gastric cancer (GC) is the fifth most frequently diagnosed cancer and the third leading cause of cancer death worldwide (1). Recent advances in surgical techniques have improved

Correspondence to: Toshiyuki Kosuga, MD, Ph.D., Division of Digestive Surgery, Department of Surgery, Kyoto Prefectural University of Medicine, 465 Kajii-cho, Kamigyo-ku, Kyoto, 6028566, Japan. Tel: +81 752515527, Fax: +81 752515522, e-mail: toti-k@koto.kpu-m.ac.jp

Key Words: Gastric cancer, gastrectomy, prognostic nutritional index, lymph node metastasis, staging. the short- and long-term outcomes of patients with GC; however, the incidence of pathological lymph node metastasis ( $\mathrm{pN}+)$ in advanced GC is high, and patients with $\mathrm{pN}+$ frequently develop cancer recurrence even after curative resection (2, 3). Therefore, perioperative adjuvant chemotherapy should be performed in such patients (4). In east Asia, although standard adjuvant care is postoperative chemotherapy alone $(5,6)$, it is being investigated whether addition of neoadjuvant chemotherapy (NAC) further improves survival of patients with a clinical diagnosis of advanced GC with lymph node metastasis ( $\mathrm{cN}+)$.

Precise prediction of $\mathrm{pN}+$ is essential to plan the optimal treatment strategy for GC. The assessment of $\mathrm{cN}+$ is generally performed by computed tomography (CT), but the diagnostic accuracy can be improved through the development of additional diagnostic tools $(3,7,8)$. The immuno-nutritional status of patients is closely associated with the extent of GC progression (9-11); therefore, the prognostic nutritional index (PNI) may be a novel predictor of $\mathrm{pN}+$ in GC. Onodera's PNI, calculated from serum albumin (Alb) and peripheral total lymphocyte counts (TLC), was found to be associated with postoperative short- and long-term outcomes in several malignancies (12-14); however, its clinical value for the prediction of $\mathrm{pN}+$ in $\mathrm{GC}$ patients remains unclear.

The present study investigated whether Onodera's PNI can predict $\mathrm{pN}+$ in patients with a clinical diagnosis of advanced GC. The diagnostic power of PNI for $\mathrm{pN}+$ was compared with that of $\mathrm{cN}+$ determined by $\mathrm{CT}$ findings. Thus, the aim of this study was to examine whether PNI alone or in combination with CT findings can aid in the precise screening of GC patients with $\mathrm{pN}+$ before surgery.

\section{Patients and Methods}

Patients. Between January 2008 and May 2013, 578 patients received surgical treatment for GC at the Division of Digestive Surgery of Kyoto Prefectural University of Medicine (KPUM) in Japan. Of these, the present study targeted only patients with a clinical diagnosis of advanced GC (cT2-T4) who underwent 
preoperative CT followed by curative gastrectomy (R0). To remove the potential influences of treatment factors on the stage of disease and diagnostic accuracy for $\mathrm{pN}+$, patients who underwent $\mathrm{NAC}$ and those undergoing non-curative gastrectomy (R1/R2) were excluded. Patients having distant metastasis of GC and those with simultaneous malignancies other than GC were also excluded. In total, 167 patients were included in this retrospective study. The present study conformed to the ethical guidelines of the World Medical Association Declaration of Helsinki-Ethical Principles for Medical Research Involving Human Subjects. Patients granted written informed consent for surgery and the use of clinical data, which was approved by the institutional review board of our institute (ERB-C-1373).

Patient and tumor characteristics. The following patient and tumor characteristics were obtained from the medical records: sex, age, smoking history, comorbid diseases (hypertension, diabetes mellitus, cardiovascular disease, cerebrovascular disease, chronic liver disease, and chronic renal failure), Borrmann type, tumor differentiation (differentiated- or undifferentiated-type adenocarcinoma), tumor location, clinical $\mathrm{T}$ stage (cT), clinical $\mathrm{N}$ stage $(\mathrm{cN})$, Onodera's PNI, pathological $\mathrm{T}$ stage $(\mathrm{pT})$, and pathological $\mathrm{N}$ stage $(\mathrm{pN})$.

Assessment of Onodera's PNI. Alb and TLC were measured within one week before surgery, and Onodera's PNI was calculated as $10 \times \mathrm{Alb}(\mathrm{g} / \mathrm{dl})+0.005 \times \mathrm{TLC}\left(\right.$ per $\left.\mathrm{mm}^{3}\right)(15)$.

Evaluation of the $c T$ and $c N$. All patients underwent upper endoscopy, upper gastrointestinal X-ray (fluoroscopy) using contrast media such as barium, and chest and abdominal CT before surgery. The cT was diagnosed using the gastroscopy and CT findings by gastroenterologists and radiologists, respectively. On the other hand, the $\mathrm{cN}$ was diagnosed using the CT findings by at least two radiologists. CT was performed at KPUM or Oike clinic (Kyoto, Japan), a consociated medical center, employing a multidetector CT with 64 or 320 layers. Contrast-enhanced CT (CECT) with iopamidol or iohexol was the recommended standard; however, patients who had iodine allergy, active asthma, or severe thyroid, heart, liver or renal disease did not undergo CECT. Lymph nodes having a minor axis of $8 \mathrm{~mm}$ or greater or a major axis of $10 \mathrm{~mm}$ or greater on $\mathrm{CT}$ were regarded as " $\mathrm{cN}+$ " according to previous studies $(3,7,8)$. In this study, none of the patients underwent endoscopic ultrasound (EUS) for the assessment of $\mathrm{cN}$.

Evaluation of the $p T$ and $p N$. Gastrectomy with lymphadenectomy was performed according to the Japanese GC treatment guidelines (JGCTG) (16). Resected specimens were microscopically examined by at least two pathologists, and $\mathrm{pT}$ and $\mathrm{pN}$ were evaluated based on the current Japanese classification of gastric carcinoma (JCGC) (17).

Statistical analysis. Receiver operating characteristic (ROC) curve analysis was performed to determine the optimal cut-off value of Onodera's PNI to predict pN+. Goodness of fit was assessed by the area under the curve (AUC), and the optimal cut-off value was determined using the Youden index. Differences between the two groups were analyzed by the $\chi^{2}$-test for categorical variables and the Student's $t$-test for continuous variables. In the analyses of associated factors for $\mathrm{pN}+$, clinical variables with $p<0.05$ in

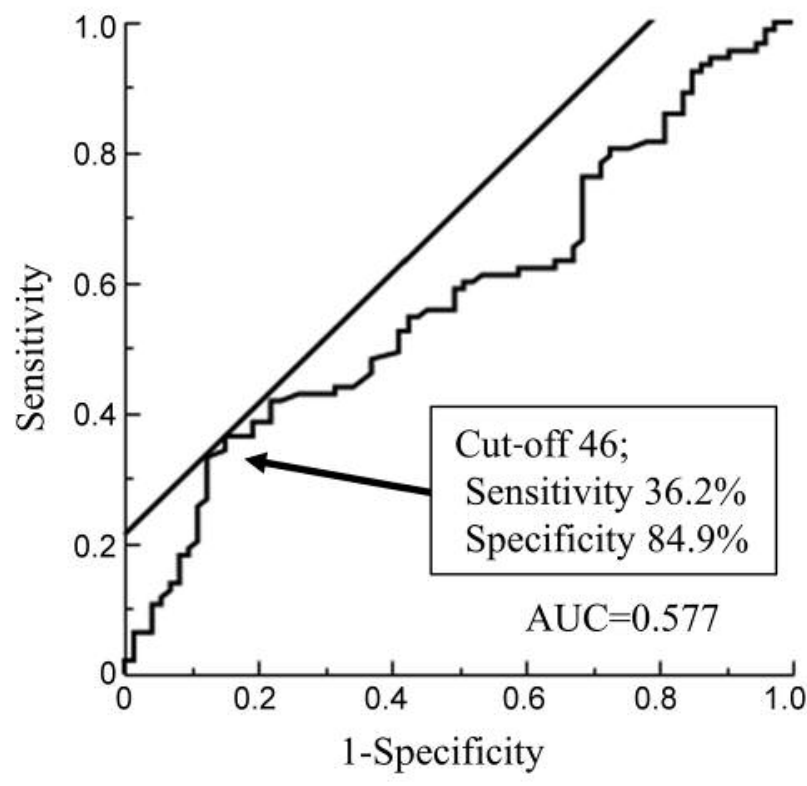

Figure 1. ROC curve for PNI as a predictive factor for $p N+$ in patients with clinical diagnosis with advanced gastric cancer. ROC: Receiver operating characteristic; PNI: prognostic nutritional index; AUC: area under the curve.

univariate analyses were entered into the multiple logistic regression model to identify independent factors. All statistical analyses were performed with JMP 12 (SAS Institute, Cary, NC, USA), and $p<0.05$ was considered to indicate statistically significant differences.

\section{Results}

Patient characteristics. The clinicopathological characteristics of the 167 patients with a clinical diagnosis of advanced GC are summarized in Table I. Patients were pathologically diagnosed with pT1 $(n=33)$ or pT2-T4 $(n=134)$. Although 73 patients $(43.7 \%)$ were diagnosed with $\mathrm{cN}+$, the number of patients actually diagnosed with $\mathrm{pN}+$ was 94 (56.3\%). The preoperative value of Onodera's PNI ranged from 26.1 to 66.2 (median, 49.5).

ROC curve analysis. The AUC value indicating the predictive power of Onodera's PNI for $\mathrm{pN}+$ was 0.577 , and the optimal cut-off value of preoperative PNI for predicting pN+ was 46 (sensitivity, 36.2\%; specificity, 84.9\%) (Figure 1). Then, all patients were divided into the two groups according to the preoperative PNI value: the low PNI $(\mathrm{PNI}<46)$ or high $\mathrm{PNI}(\mathrm{PNI} \geq 46)$ group.

Clinicopathological factors associated with preoperative $P N I$. The differences in the clinicopathological factors 
Table I. Clinicopathological characteristics of patients.

\begin{tabular}{|c|c|c|c|c|}
\hline & $\begin{array}{c}\text { All patients } \\
(\mathrm{n}=167)\end{array}$ & $\begin{array}{c}\mathrm{PNI}<46 \\
(\mathrm{n}=45)\end{array}$ & $\begin{array}{l}\mathrm{PNI} \geq 46 \\
(\mathrm{n}=122)\end{array}$ & $p$-Value \\
\hline \multicolumn{5}{|l|}{ Clinical characteristics } \\
\hline Gender, n (\%) & & & & 0.974 \\
\hline Male & $111(66.5)$ & $30(66.7)$ & $81(66.5)$ & \\
\hline Female & $56(33.5)$ & $15(33.3)$ & $41(33.5)$ & \\
\hline \multicolumn{4}{|l|}{ Age (years) } & 0.002 \\
\hline Median (range) & $69(29-89)$ & $73(56-85)$ & $68(29-89)$ & \\
\hline Mean \pm SD & $67.7 \pm 11.6$ & $72.2 \pm 8.0$ & $66.1 \pm 12.3$ & \\
\hline \multicolumn{4}{|l|}{ Smoking history } & 0.557 \\
\hline Present & $73(43.7)$ & $18(40.0)$ & $55(45.1)$ & \\
\hline Absent & $94(56.3)$ & $27(60.0)$ & $67(54.9)$ & \\
\hline \multicolumn{4}{|l|}{ Hypertension } & 0.681 \\
\hline Present & $48(28.7)$ & $14(31.1)$ & $34(27.9)$ & \\
\hline Absent & $119(71.3)$ & $31(68.9)$ & $88(72.1)$ & \\
\hline \multicolumn{4}{|l|}{ Diabetes mellitus } & 0.143 \\
\hline Present & $29(17.4)$ & $11(24.4)$ & $18(14.8)$ & \\
\hline Absent & $138(82.6)$ & $34(75.6)$ & $104(85.2)$ & \\
\hline \multicolumn{4}{|l|}{ Cardiovascular disease } & 0.006 \\
\hline Present & $25(15.0)$ & $13(28.9)$ & $12(9.8)$ & \\
\hline Absent & $142(85.0)$ & $32(71.1)$ & $110(90.2)$ & \\
\hline \multicolumn{4}{|l|}{ Cerebrovascular disease } & 0.309 \\
\hline Present & $12(7.2)$ & $5(11.1)$ & $7(5.7)$ & \\
\hline Absent & $155(92.8)$ & $40(88.9)$ & $115(94.3)$ & \\
\hline \multicolumn{4}{|l|}{ Chronic liver disease } & 1.000 \\
\hline Present & $5(3.0)$ & $1(2.2)$ & $4(3.3)$ & \\
\hline Absent & $162(97.0)$ & $44(97.8)$ & $118(96.7)$ & \\
\hline \multicolumn{4}{|l|}{ Chronic renal failure } & 0.345 \\
\hline Present & $6(3.6)$ & $3(6.7)$ & $3(2.5)$ & \\
\hline Absent & $161(96.4)$ & $42(93.3)$ & $119(97.5)$ & \\
\hline \multicolumn{4}{|l|}{ Borrmann type } & 0.053 \\
\hline 0 & $28(16.8)$ & $2(4.4)$ & $26(21.3)$ & \\
\hline 1 & $17(10.2)$ & $7(16.6)$ & $10(8.2)$ & \\
\hline 2 & $44(26.4)$ & $11(24.4)$ & $33(27.0)$ & \\
\hline 3 & $61(36.5)$ & $18(40.0)$ & $43(35.3)$ & \\
\hline 4 & $17(10.1)$ & $7(15.6)$ & $10(8.2)$ & \\
\hline \multicolumn{4}{|l|}{ Tumor differentiation } & 0.065 \\
\hline Differentiated type & $79(47.3)$ & $16(35.6)$ & $63(51.6)$ & \\
\hline Undifferentiated type & $88(52.7)$ & $29(64.4)$ & $59(48.4)$ & \\
\hline \multicolumn{4}{|l|}{ Tumor location, n (\%) } & 0.084 \\
\hline Upper & $46(27.6)$ & $10(22.2)$ & $36(29.5)$ & \\
\hline Middle & $55(32.9)$ & $11(24.4)$ & $44(36.1)$ & \\
\hline Lower & $66(39.5)$ & $24(53.4)$ & $42(34.4)$ & \\
\hline \multicolumn{3}{|l|}{$\mathrm{cT}, \mathrm{n}(\%)$} & & 0.011 \\
\hline $\mathrm{T} 2$ & $117(70.0)$ & $26(57.8)$ & 91 (74.6) & \\
\hline $\mathrm{T} 3$ & $41(24.6)$ & $13(28.9)$ & $28(22.9)$ & \\
\hline $\mathrm{T} 4$ & $9(5.4)$ & $6(13.3)$ & $3(2.5)$ & \\
\hline \multicolumn{4}{|l|}{$\mathrm{cN}, \mathrm{n}(\%)$} & 0.671 \\
\hline N0 (negative) & $94(56.3)$ & $23(51.1)$ & $71(58.2)$ & \\
\hline $\mathrm{N}+($ positive $)$ & $73(43.7)$ & $22(48.9)$ & $51(41.8)$ & \\
\hline PNI & & & & $<0.001$ \\
\hline \multirow[t]{2}{*}{ Median (range) } & 49.5 & 43.5 & 51.5 & \\
\hline & $(26.1-66.2)$ & $(26.1-45.9)$ & $(46.1-66.2)$ & \\
\hline Mean \pm SD & $49.5 \pm 6.2$ & $42.1 \pm 4.4$ & $52.3 \pm 4.1$ & \\
\hline
\end{tabular}

between the low and high PNI groups are summarized in Table I. Low PNI $(\mathrm{PNI}<46)$ was significantly associated with older age, presence of cardiovascular disease, advanced cT

\begin{tabular}{lcccc}
\hline & $\begin{array}{c}\text { All patients } \\
(\mathrm{n}=167)\end{array}$ & $\begin{array}{c}\mathrm{PNI}<46 \\
(\mathrm{n}=45)\end{array}$ & $\begin{array}{l}\text { PNI } \geq 46 \\
(\mathrm{n}=122)\end{array}$ & $p$-Value \\
\hline $\begin{array}{l}\text { Pathological characteristics } \\
\text { pT, n (\%) }\end{array}$ & & & & \\
T1 & $33(19.8)$ & $6(13.3)$ & $27(22.1)$ & 0.284 \\
T2 & $36(21.6)$ & $9(20.0)$ & $27(22.1)$ & \\
T3 & $52(31.1)$ & $13(28.9)$ & $39(32.0)$ & \\
T4 & $46(27.5)$ & $17(37.8)$ & $29(23.8)$ & \\
pN, n (\%) & & & \multicolumn{2}{l}{0.002} \\
N0 (negative) & $73(43.7)$ & $11(24.4)$ & $62(50.8)$ & \\
N+ (positive) & $94(56.3)$ & $34(75.6)$ & $60(49.2)$ & \\
\hline
\end{tabular}

SD: Standard deviation; cT: clinical T stage; $\mathrm{cN}$ : clinical lymph node metastasis; PNI: prognostic nutritional index; pT: pathological T stage; $\mathrm{pN}$ : pathological lymph node metastasis.

category, and $\mathrm{pN}+$. Although the differences were not statistically significant, low PNI tended to correlate with Borrmann Type, tumor differentiation, and tumor location. However, preoperative PNI did not show significant correlation with $\mathrm{cN}$ and $\mathrm{pT}$.

Clinical factors associated with $\mathrm{pN+}$. The univariate and multivariate analyses of clinical factors associated with $\mathrm{pN}+$ in patients with a clinical diagnosis of advanced GC are shown in Table II. pN+ was significantly associated with undifferentiated-type adenocarcinoma, $\mathrm{cN}+$ and low PNI in the univariate analysis. The multivariate analysis identified tumor differentiation [odds ratio $(\mathrm{OR})=2.032$; $95 \%$ confidence interval $(\mathrm{CI})=1.060-3.947, \mathrm{p}=0.033], \quad \mathrm{cN}$ $(\mathrm{OR}=2.323 ; \quad 95 \% \mathrm{CI}=1.204-4.579, \quad \mathrm{p}=0.012)$ and $\mathrm{PNI}$ $(\mathrm{OR}=2.905 ; 95 \% \mathrm{CI}=1.347-6.638, \mathrm{p}=0.006)$ as independent associated factors.

Clinical value of Onodera's PNI for the prediction of $p N+$. The diagnostic accuracy of preoperative PNI and $\mathrm{cN}+$ for $\mathrm{pN}+$ in patients with a clinical diagnosis of advanced GC is presented in Table III. The sensitivity and specificity of PNI for $\mathrm{pN}+$ were $36.2 \%$ and $84.9 \%$, respectively. Thus, the sensitivity was lower and the specificity was higher than those (sensitivity; $52.1 \%$, and specificity; $68.5 \%$ ) of $\mathrm{cN}+$ determined by the $\mathrm{CT}$ findings. To further explore the clinical value of PNI as a complementary diagnostic tool to $\mathrm{CT}$, the diagnostic accuracies of PNI for $\mathrm{pN}+$ were separately examined according to the $\mathrm{cN}$ status (Table IV). When the subjects were limited to patients with $\mathrm{cN}+$, the specificity and positive predictive value (PPV) for $\mathrm{pN}+$ became markedly high (91.3\% and $90.5 \%$, respectively). Even in patients with $\mathrm{cN} 0$, the specificity and PPV for $\mathrm{pN}+$ were $82.0 \%$ and $62.5 \%$, respectively. 
Table II. Associated clinical factors for $\mathrm{pN}+$.

\begin{tabular}{|c|c|c|c|c|c|c|c|c|}
\hline \multirow[t]{4}{*}{ Variables } & \multicolumn{8}{|c|}{ Pathological lymph node metastasis } \\
\hline & \multicolumn{5}{|c|}{ Univariate analysis } & \multicolumn{3}{|c|}{ Multivariate analysis } \\
\hline & \multicolumn{2}{|c|}{$\mathrm{pN}+$} & \multicolumn{2}{|c|}{$\mathrm{pNO}$} & \multirow[t]{2}{*}{$p$-Value } & \multirow[t]{2}{*}{ OR } & \multirow[t]{2}{*}{$95 \% \mathrm{CI}$} & \multirow[t]{2}{*}{$p$-Value } \\
\hline & n (94) & $\%$ & n (73) & $\%$ & & & & \\
\hline Gender & & & & & 0.139 & & & \\
\hline Male & 58 & 61.7 & 53 & 72.6 & & & & \\
\hline Female & 36 & 38.3 & 20 & 27.4 & & & & \\
\hline Age & & & & & 0.405 & & & \\
\hline$<65$ & 29 & 30.9 & 27 & 37.0 & & & & \\
\hline$\geq 65$ & 65 & 69.1 & 46 & 63.0 & & & & \\
\hline Smoking history & & & & & 0.978 & & & \\
\hline Present & 41 & 43.6 & 32 & 43.8 & & & & \\
\hline Absent & 53 & 56.4 & 41 & 56.2 & & & & \\
\hline Hypertension & & & & & 0.995 & & & \\
\hline Present & 27 & 28.7 & 21 & 28.8 & & & & \\
\hline Absent & 67 & 71.3 & 52 & 71.2 & & & & \\
\hline Diabetes mellitus & & & & & 0.586 & & & \\
\hline Present & 15 & 16.0 & 14 & 19.2 & & & & \\
\hline Absent & 79 & 84.0 & 59 & 80.8 & & & & \\
\hline Cardiovascular disease & & & & & 0.685 & & & \\
\hline Present & 15 & 16.0 & 10 & 13.7 & & & & \\
\hline Absent & 79 & 84.0 & 63 & 86.3 & & & & \\
\hline Cerebrovascular disease & & & & & 1.000 & & & \\
\hline Present & 7 & 7.4 & 5 & 6.9 & & & & \\
\hline Absent & 87 & 92.6 & 68 & 93.1 & & & & \\
\hline Chronic liver disease & & & & & - & & & \\
\hline Present & 0 & 0.0 & 5 & 6.9 & & & & \\
\hline Absent & 94 & 100.0 & 68 & 93.1 & & & & \\
\hline Chronic renal failure & & & & & 1.000 & & & \\
\hline Present & 3 & 3.2 & 3 & 4.1 & & & & \\
\hline Absent & 91 & 96.8 & 70 & 95.9 & & & & \\
\hline Borrmann type & & & & & 0.512 & & & \\
\hline $0 / 1 / 2$ & 48 & 51.1 & 41 & 56.2 & & & & \\
\hline $3 / 4$ & 46 & 48.9 & 32 & 43.8 & & & & \\
\hline Tumor differentiation & & & & & 0.020 & & & 0.033 \\
\hline Differentiated type & 37 & 39.4 & 42 & 57.5 & & 1 & & \\
\hline Undifferentiated type & 57 & 60.6 & 31 & 42.5 & & 2.032 & $1.060-3.947$ & \\
\hline Tumor location & & & & & 0.914 & & & \\
\hline Upper & 34 & 36.2 & 27 & 37.0 & & & & \\
\hline Middle/Lower & 60 & 63.8 & 46 & 63.0 & & & & \\
\hline $\mathrm{cT}$ & & & & & 0.771 & & & \\
\hline $\mathrm{T} 2$ & 65 & 69.2 & 52 & 71.2 & & & & \\
\hline $\mathrm{T} 3 / \mathrm{T} 4$ & 29 & 30.8 & 21 & 28.8 & & & & \\
\hline $\mathrm{cN}$ & & & & & 0.013 & & & 0.012 \\
\hline No & 45 & 47.9 & 49 & 67.1 & & 1 & & \\
\hline $\mathrm{N}+$ & 49 & 52.1 & 24 & 32.9 & & 2.323 & $1.204-4.579$ & \\
\hline PNI & & & & & 0.002 & & & 0.006 \\
\hline Low $(<46)$ & 34 & 36.2 & 11 & 15.1 & & 2.905 & $1.347-6.638$ & \\
\hline High $(>46)$ & 60 & 63.8 & 62 & 84.9 & & 1 & & \\
\hline
\end{tabular}

PNI: Prognostic nutritional index; cT: clinical T stage; cN: clinical lymph node metastasis; pN: pathological lymph node metastasis.

\section{Discussion}

Onodera's PNI, originally developed as a predictor of complications after colorectal cancer surgery in Japan, is increasingly used for hospitalized patients to evaluate the immuno-nutritional status (15). The PNI is readily available by blood tests only, and a PNI value of at least 50 is categorized as normal nutritional status, with values between 
Table III. Diagnostic accuracy of $c N+$ and PNI for $p N+$.

A: $\mathrm{cN}+$ determined by the $\mathrm{CT}$ findings

\begin{tabular}{lccc}
\hline & $\mathrm{pN}+$ & $\mathrm{pN} 0$ & $\mathrm{n}$ \\
\hline $\mathrm{cN}+$ & 49 & 23 & 72 \\
$\mathrm{cN} 0$ & 45 & 50 & 95 \\
$\mathrm{n}$ & 94 & 73 & 167 \\
\hline
\end{tabular}

B: PNI

\begin{tabular}{lccr}
\hline & $\mathrm{pN}+$ & $\mathrm{pN} 0$ & $\mathrm{n}$ \\
\hline Low PNI $(<46)$ & 34 & 11 & 45 \\
High PNI $(>46)$ & 60 & 62 & 122 \\
$\mathrm{n}$ & 94 & 73 & 167 \\
\hline
\end{tabular}

C: Diagnostic accuracy for $\mathrm{pN}+$

\begin{tabular}{lcc}
\hline & \multicolumn{2}{c}{ Pathological lymph node metastasis } \\
\cline { 2 - 3 } & cN+(CT findings) & PNI \\
\hline Sensitivity & $52.1 \%$ & $36.2 \%$ \\
Specificity & $68.5 \%$ & $84.9 \%$ \\
Positive predictive value & $68.1 \%$ & $75.6 \%$ \\
Negative predictive value & $52.6 \%$ & $50.8 \%$ \\
\hline
\end{tabular}

PNI: Prognostic nutritional index; CT: computed tomography.

45 and 50 indicating mild malnutrition, values between 40 and 45 indicating moderate to severe malnutrition, and values lower than 40 indicating serious malnutrition. The present study set the optimal cut-off value of PNI for predicting $\mathrm{pN}+$ at 46 according to the ROC curve analysis, which reflects mild to moderate malnutrition.

When the cut-off value was set at 46 , preoperative PNI was identified to be an independent predictor for $\mathrm{pN}+$ in patients with a clinical diagnosis of advanced GC (cT2-T4). Meanwhile, when targeting 280 patients with a clinical diagnosis of early GC (cT1) who underwent curative gastrectomy at KPUM in the same study period, a $\mathrm{PNI}<46$ was not useful in the prediction of $\mathrm{pN}+$ (data not shown). In patients with cT2-T4, a PNI $<46$ detected $\mathrm{pN}+$ with a lower sensitivity and higher specificity than $\mathrm{cN}+$ determined by the CT findings. Accordingly, a low PNI can be useful for the definitive diagnosis of $\mathrm{pN}+$ in advanced $\mathrm{GC}$, whereas care should be taken for the high occurrence of false-negatives when using PNI alone for the prediction of $\mathrm{pN}+$. Because $\mathrm{cN}+$ was also identified to be an independent predictor for $\mathrm{pN}+$, it may be more beneficial if preoperative PNI is used in combination with the CT findings. Notably, when the subjects were limited to those with cT2-T4 with $\mathrm{cN}+$, the sensitivity and PPV for $\mathrm{pN}+$ increased further $(91.3 \%$ and $90.5 \%$, respectively).
Table IV. Diagnostic accuracy of PNI for pN+ separately examined according to $\mathrm{cN}$ in patients with advanced gastric cancer.

A: $\mathrm{cN}+$

\begin{tabular}{lccc}
\hline & $\mathrm{pN}+$ & $\mathrm{pN} 0$ & $\mathrm{n}$ \\
\hline Low PNI $(<46)$ & 19 & 2 & 21 \\
High PNI $(>46)$ & 30 & 21 & 51 \\
$\mathrm{n}$ & 49 & 23 & 72 \\
\hline \multicolumn{3}{c}{ Pathological lymph node metastasis } \\
& PNI \\
\hline Sensitivity & \multicolumn{2}{c}{$38.8 \%$} \\
Specificity & $91.3 \%$ \\
Positive predictive value & $90.5 \%$ \\
Negative predictive value & $41.2 \%$ \\
\hline
\end{tabular}

B: cNO

\begin{tabular}{lccc}
\hline & $\mathrm{pN}+$ & $\mathrm{pN} 0$ & $\mathrm{n}$ \\
\hline Low PNI $(<46)$ & 15 & 9 & 24 \\
High PNI $(>46)$ & 30 & 41 & 71 \\
$\mathrm{n}$ & 45 & 50 & 95 \\
\hline \multicolumn{3}{c}{ Pathological lymph node metastasis } \\
& \multicolumn{2}{c}{ PNI } \\
\hline \multicolumn{3}{c}{$33.3 \%$} \\
Sensitivity & \multicolumn{2}{c}{$82.0 \%$} \\
Specificity & $62.5 \%$ \\
Positive predictive value & $57.7 \%$ \\
Negative predictive value & \\
\hline
\end{tabular}

PNI: Prognostic nutritional index.

Preoperative PNI may aid in clarifying the extent of lymph node dissection. Based on the high specificity and PPV for $\mathrm{pN}+$, patients with a $\mathrm{PNI}<46$ and/or $\mathrm{cN}+$ should be treated with D2 lymphadenectomy as determined by the JGCTG (16). On the other hand, low PNI may also be associated with the occurrence of postoperative complications due to tissue vulnerability, impaired wound healing and high susceptibility to infection (9-11). Kanda et al. have previously identified $\mathrm{PNI}<47$ as an independent predictor of postoperative morbidity in GC patients undergoing R0 (9). However, Sakurai et al. have reported that PNI $<45$ was not significantly associated with the occurrence of postoperative intraabdominal complications in GC patients undergoing R0 (10). Although the influence of PNI on the occurrence of postoperative morbidity must be discussed further, surgeons should carefully proceed with $\mathrm{R} 0$ under the assumption of $\mathrm{pN}+$, and provide detailed perioperative management, including nutritional support, especially for advanced GC patients with low PNI and $\mathrm{cN}+(18-20)$. 
When the ideal target of NAC is advanced GC with $\mathrm{pN}+$, PNI may aid in the definitive selection of reliable candidates among advanced GC patients with $\mathrm{cN}+$. In particular, when considering the use of highly toxic chemotherapeutic agents, the clinical PNI value can be considerable because of the minimal occurrence of false-positives. Many researchers have previously demonstrated that PNI can be a predictor of overall and cancer-specific survival in patients with GC, independent of the pathological stage of GC (9-11). Therefore, a low PNI itself may be a better indication for NAC. However, Kanda et al. have found that advanced GC patients with $\mathrm{PNI}<47$ received no survival benefit from postoperative adjuvant chemotherapy because of further deterioration of immunocompetence induced by the adverse effects of chemotherapy that accelerated tumor progression (9). Although the regimen, intensity, and effects of adjuvant chemotherapy may differ between preoperative and postoperative treatments, it should be performed with effective nutritional support in order to prevent further deterioration of the immuno-nutritional status of patients with a low PNI.

The present study has some limitations. This was a retrospective study with a small sample size, which may limit the statistical power and generate statistical bias. Although the optimal cut-off value of PNI for predicting $\mathrm{pN}+$ was set at 46 in this study, the lower sensitivity is a problem to be solved. Furthermore, the present study did not reveal specific measures to improve the short- and long-term outcomes of GC patients with low PNI. However, to the best of our knowledge, this study is the first to present the novel potential of PNI for the prediction of $\mathrm{pN}+$ in patients with clinical diagnosis of advanced GC. Notably, in combination with the CT findings, PNI may aid in the definitive diagnosis of $\mathrm{pN}+$ with a markedly high specificity and PPV. The results of the present study, as well as the optimal cut-off value of PNI, need to be validated in further studies with large sample sizes for the precise screening of GC patients with $\mathrm{pN}+$ before surgery.

\section{Conclusion}

Onodera's PNI was able to predict $\mathrm{pN}+$ with a high specificity in patients with clinical diagnosis of advanced GC; therefore, PNI may aid in the definitive diagnosis of $\mathrm{pN}+$, especially in combination with $\mathrm{CT}$ findings.

\section{Conflicts of Interest}

The Authors declare that they have no conflicts of interest regarding this study.

\section{Authors' Contributions}

Study conception and design: T Kosuga; Acquisition of data: $\mathrm{T}$ Kosuga, T Konishi; Analysis and interpretation of data: T Kosuga,
T Konishi, T Kubota, KS, HK, AS, KO, HF, MK, TA, RM, YM, YK, HI, MN; Drafting of manuscript: T Kosuga, and T Konishi; Critical revision of manuscript: EO.

\section{References}

1 Bray F, Ferlay J, Soerjomataram I, Siegel RL, Torre LA and Jemal A: Global cancer statistics 2018: Globocan estimates of incidence and mortality worldwide for 36 cancers in 185 countries. CA Cancer J Clin 68(6): 394-424, 2018. PMID: 30207593. DOI: $10.3322 /$ caac. 21492

2 Komatsu S, Ichikawa D, Nishimura M, Kosuga T, Okamoto K, Konishi H, Shiozaki A, Fujiwara H and Otsuji E: Evaluation of prognostic value and stage migration effect using positive lymph node ratio in gastric cancer. Eur J Surg Oncol 43(1): 203-209, 2017. PMID: 27595506. DOI: 10.1016/j.ejso.2016.08.002

3 Kudou M, Kosuga T, Kubota T, Okamoto K, Komatsu S, Shoda K, Konishi H, Shiozaki A, Fujiwara H, Arita T, Morimura R, Murayama Y, Kuriu Y, Ikoma H, Nakanishi M and Otsuji E: Value of preoperative pet-ct in the prediction of pathological stage of gastric cancer. Ann Surg Oncol 25(6): 1633-1639, 2018. PMID: 29626306. DOI: 10.1245/s10434-018-6455-0

4 Cunningham D, Allum WH, Stenning SP, Thompson JN, Van de Velde CJ, Nicolson M, Scarffe JH, Lofts FJ, Falk SJ, Iveson TJ, Smith DB, Langley RE, Verma M, Weeden S, Chua YJ and Participants MT: Perioperative chemotherapy versus surgery alone for resectable gastroesophageal cancer. N Engl J Med 355(1): 11-20, 2006. PMID: 16822992. DOI: 10.1056/ NEJMoa055531

5 Bang YJ, Kim YW, Yang HK, Chung HC, Park YK, Lee KH, Lee KW, Kim YH, Noh SI, Cho JY, Mok YJ, Ji J, Yeh TS, Button P, Sirzen F and Noh SH: Adjuvant capecitabine and oxaliplatin for gastric cancer after d2 gastrectomy (classic): A phase 3 open-label, randomised controlled trial. Lancet 379(9813): 315-321, 2012. PMID: 22226517. DOI: 10.1016/ S0140-6736(11)61873-4

6 Sakuramoto S, Sasako M, Yamaguchi T, Kinoshita T, Fujii M, Nashimoto A, Furukawa H, Nakajima T, Ohashi Y, Imamura H, Higashino M, Yamamura Y, Kurita A and Arai K: Adjuvant chemotherapy for gastric cancer with s-1, an oral fluoropyrimidine. N Engl J Med 357(18): 1810-1820, 2007. PMID: 17978289. DOI: 10.1056/NEJMoa072252

7 Fukagawa T, Katai H, Mizusawa J, Nakamura K, Sano T, Terashima M, Ito S, Yoshikawa T, Fukushima N, Kawachi Y, Kinoshita T, Kimura Y, Yabusaki H, Nishida Y, Iwasaki Y, Lee SW, Yasuda T and Sasako M: A prospective multi-institutional validity study to evaluate the accuracy of clinical diagnosis of pathological stage iii gastric cancer (jcog1302a). Gastric Cancer 21(1): 68-73, 2018. PMID: 28194522. DOI: $10.1007 / \mathrm{s} 10120-$ 017-0701-1

8 Hasegawa S, Yoshikawa T, Shirai J, Fujikawa H, Cho H, Doiuchi T, Yoshida T, Sato T, Oshima T, Yukawa N, Rino Y, Masuda $\mathrm{M}$ and Tsuburaya A: A prospective validation study to diagnose serosal invasion and nodal metastases of gastric cancer by multidetector-row ct. Ann Surg Oncol 20(6): 2016-2022, 2013. PMID: 23266583. DOI: 10.1245/s 10434-012-2817-1

9 Kanda M, Mizuno A, Tanaka C, Kobayashi D, Fujiwara M, Iwata N, Hayashi M, Yamada S, Nakayama G, Fujii T, Sugimoto H, Koike M, Takami H, Niwa Y, Murotani K and Kodera Y: Nutritional predictors for postoperative short-term and long-term 
outcomes of patients with gastric cancer. Medicine (Baltimore) 95(24): e3781, 2016. PMID: 27310954. DOI: 10.1097/MD.000 0000000003781

10 Sakurai K, Ohira M, Tamura T, Toyokawa T, Amano R, Kubo N, Tanaka H, Muguruma K, Yashiro M, Maeda K and Hirakawa $\mathrm{K}$ : Predictive potential of preoperative nutritional status in longterm outcome projections for patients with gastric cancer. Ann Surg Oncol 23(2): 525-533, 2016. PMID: 26307230. DOI: 10.1245/s10434-015-4814-7

11 Jiang N, Deng JY, Ding XW, Ke B, Liu N, Zhang RP and Liang $\mathrm{H}$ : Prognostic nutritional index predicts postoperative complications and long-term outcomes of gastric cancer. World J Gastroenterol 20(30): 10537-10544, 2014. PMID: 25132773. DOI: $10.3748 /$ wjg.v20.i30.10537

12 Kanda M, Fujii T, Kodera Y, Nagai S, Takeda S and Nakao A: Nutritional predictors of postoperative outcome in pancreatic cancer. Br J Surg 98(2): 268-274, 2011. PMID: 20960457. DOI: 10.1002/bjs. 7305

13 Okamura Y, Ashida R, Ito T, Sugiura T, Mori K and Uesaka K: Preoperative neutrophil to lymphocyte ratio and prognostic nutritional index predict overall survival after hepatectomy for hepatocellular carcinoma. World J Surg 39(6): 1501-1509, 2015. PMID: 25670038. DOI: 10.1007/s00268-015-2982-z

14 Schwegler I, von Holzen A, Gutzwiller JP, Schlumpf R, Muhlebach S and Stanga Z: Nutritional risk is a clinical predictor of postoperative mortality and morbidity in surgery for colorectal cancer. Br J Surg 97(1): 92-97, 2010. PMID: 20013933. DOI: $10.1002 /$ bjs.6805

15 Onodera T, Goseki N and Kosaki G: Prognostic nutritional index in gastrointestinal surgery of malnourished cancer patients. Nihon Geka Gakkai Zasshi 85(9): 1001-1005, 1984. PMID: 6438478.
16 Japanese gastric cancer treatment guidelines 2014 (ver. 4). Gastric Cancer 20(1): 1-19, 2017. PMID: 27342689. DOI: $10.1007 / \mathrm{s} 10120-016-0622-4$

17 Japanese classification of gastric carcinoma: 3rd english edition. Gastric Cancer 14(2): 101-112, 2011. PMID: 21573743. DOI: 10.1007/s 10120-011-0041-5

18 Bowrey DJ, Baker M, Halliday V, Thomas AL, Pulikottil-Jacob $\mathrm{R}$, Smith K, Morris T and Ring A: A randomised controlled trial of six weeks of home enteral nutrition versus standard care after oesophagectomy or total gastrectomy for cancer: Report on a pilot and feasibility study. Trials 16: 531, 2015. PMID: 26590903. DOI: 10.1186/s13063-015-1053-y

19 Braga M, Gianotti L, Vignali A and Carlo VD: Preoperative oral arginine and n-3 fatty acid supplementation improves the immunometabolic host response and outcome after colorectal resection for cancer. Surgery 132(5): 805-814, 2002. PMID: 12464864. DOI: $10.1067 / \mathrm{msy} .2002 .128350$

$20 \mathrm{Xu} \mathrm{J}$, Zhong Y, Jing D and Wu Z: Preoperative enteral immunonutrition improves postoperative outcome in patients with gastrointestinal cancer. World J Surg 30(7): 1284-1289, 2006. PMID: 16830214. DOI: 10.1007/s00268-005-0756-8

Received October 23, 2019

Revised November 2, 2019

Accepted November 4, 2019 